\title{
19 Gender, Masculinity, and Safety in the Changing Lao-Thai Migration Landscape
}

\author{
Roy Huijsmans ${ }^{1}$
}

\begin{abstract}
Recent policy debates on migration in the Greater Mekong Subregion have put increasing emphasis on migrant safety, which has taken the form of opening legal channels of migration. Whereas the discourse on migrant safety revolves around gendered emphases in vulnerability, foregrounding female migrants' vulnerability and muting male migrants' vulnerability, policy interventions to make migration safer are too often framed as gender-neutral. In this chapter I focus on Lao employment agencies as a key technique in the management of LaoThai cross-border migration. I argue that employment agencies are embedded in a masculine policy landscape and I contest them as gender-neutral techniques by demonstrating how these agencies and the policy architecture in which they are situated produce significant degrees of male privilege when it comes to accessing supposedly safe forms of migration. Yet male privilege is limited, as migrating through these supposedly safe channels of migration may in fact increase male migrants' vulnerability. However, I argue that young men's motivations for migrating through these expensive legal channels can only in part be understood by looking at their material effects on migrant vulnerability. Instead, this practice should rather be interpreted as a modern version of the cultural style of hegemonic masculinity through which young men deal with protection from danger in the risky exercise of migration.
\end{abstract}

Keywords: Gender, Lao PDR, masculinities, migration, policy, Thailand.

\subsection{Introduction}

Recent policy debates on migration have put increasing emphasis on improving migrant safety. This is driven by strongly gendered constructions of migrant vulnerability in which female migrants' vulnerability is emphasized and often essentialized and male migrants' vulnerability is silenced or ignored. Concerns about a pattern of so-called feminization of migration (e.g. Gaetano/Yeoh 20I0) have further contributed to a lack of attention to male migrants' vulnerability, despite the fact that men still constitute a large share of the migrant population-including in the Greater Mekong Subregion (GMS).

The GMS is frequently highlighted in relation to concerns about migrant vulnerability. This is most evident in the portrayal of the GMS as a trafficking

1 Roy Huijsmans is Lecturer in Children and Youth Studies at the International Institute of Social Studies (ISS) in the Hague, the Netherlands. hotspot (UN-ESCAP 2000; ILO 2003b: 29; David/ Gallagher/Holmes/Moskowitz 20II: I). Human trafficking is one of the most dramatic representations of migrant vulnerability and the explicit emphasis on 'women and children' ${ }^{2}$ highlights how constructs of migrant vulnerability are strongly gendered and generational. Recent attempts to broaden anti-trafficking legislation and interventions, in order to make them inclusive of (adult) male victims (e.g. ILO 2008: 6-7; David/Gallagher/Holmes/Moskowitz 20II: II; UNIAP n.d.), have, so far, done little to alter such dominant constructs of migrant vulnerability.

Sparse attention to male migrant vulnerability in the context of both anti-trafficking and migration policy is substantially due, I will argue, to the social con-

2 This is evident from the Protocol to Prevent, Suppress and Punish Trafficking in Persons, Especially Women and Children, of the United Nations Convention against Transnational Organized Crime (2000), also commonly known as the 'Palermo Convention'. 
struction of masculinity. Hegemonic notions of masculinity construct hardships experienced by male migrants as something to overcome and conducive to the formation of masculinity as conceived in the hegemonic notion. This disassociates the vulnerability of male migrants from questions about the social production of male vulnerability and, specifically, the role of seemingly gender-neutral 'safe migration' policy frameworks in producing degrees of male vulnerability.

Policy efforts to address migrant vulnerability have over recent years undergone a gradual shift. The initial exclusive focus on the (potential) migrants deemed most vulnerable (young girls), through the human trafficking discourse, is now increasingly combined with broader efforts to make migration 'safer' (ILO 2003a; Dottridge 2006: II). In this chapter I concentrate on a key policy area that is presented as making migration safer. This concerns the "improving, enlarging and creating [of] additional legal labour migration channels that may substitute for the trafficking of children and women into exploitative situations" (ILO 2003a: 2).

In this chapter I unravel the apparent gender neutrality in the architecture of the legal channels of migration. In addition, I shed light on the practice dimension of migration policies presented as improving migrant safety, by analysing how such policies play out in particular, often deeply gendered, migrant landscapes. These two lines of analysis illuminate the male privilege embedded in policy approaches to safe migration. Yet the analysis also shows male privilege to be limited, as men's privilege in accessing supposedly safe channels of migration in fact increases rather than decreases the condition of migrant vulnerability. Lastly, by highlighting a number of 'mistranslations' of policy in local contexts I stress the importance of ethnography in policy-related research. This shows that policy as manifesting in local contexts is never static, given, or uniform, but always and necessarily in the making, negotiated, and plural.

In making this case I will focus on Lao-Thai migration in the middle Mekong Valley and on the role of 'employment agencies' specifically. ${ }^{3}$ In global policy discourses on the creation of legal channels of migration, employment agencies play a key role (Rudnyckyj 2004; Martin 2005; World Bank 2006; Chantavanich 2008; Pijpers 20IO; Xiang 20I2). These agencies are

3 In this chapter the term "employment agencies" is used. These agencies are also referred to as "human resources companies" (Rudnyckyj 2004) or "employment services agencies" (Martin 2005). envisioned as actors who help to improve migrant safety in various ways, including equipping migrants with a documented status, transparent recruitment practices, providing pre-migration training sessions for migrants, establishing contractual arrangements between employers and migrant workers in accordance with relevant laws, and protecting migrant workers from exploitation by ensuring that contractual arrangements are respected (e.g. Ministry of Labour and Social Welfare, Lao PDR 2002a).

Lao employment agencies are relatively new actors in the emerging Lao migration regime, hence the empirical prevalence of migration through employment agencies remains low. Yet a focus on this particular intervention is justified by the important role attributed to such agencies globally and within the Lao People's Democratic Republic (Lao PDR). In addition, the Lao-Thai case fits the purpose of this chapter since it constitutes a case in which concerns about migrant safety are highly gendered, yet responded to in seemingly gender-neutral terms. Moreover, a focus on Lao PDR contributes to filling important knowledge gaps on migration research in the GMS, which has so far paid little attention to Lao migration. The few studies doing so typically focus on Lao migrants at their destination in Thailand without linking this to research at their sites of origin.

The chapter is organized as follows. The next section briefly explains the methodology and data sources before moving on to a discussion of the emerging body of work on masculinities and migration and its relevance for the Lao case discussed here. This is followed by a multi-scalar analysis of the introduction of Lao employment agencies as situated in the emerging Lao migration regime. Having mapped the discursive and politico-economic architecture of the Lao migration regimes, the final sections of the chapter unravel the gendered working of employment agencies. This is done by focusing on the gendered construction of categories of migrants and legitimate migrant work, complemented with analyses of the lived experience of migrating through employment agencies.

\subsection{Methodology and Data}

The empirical material presented in this chapter stems from two sources. First, material collected for an overview report sponsored by the International Labour Organisation (ILO), using semi-structured interviews predominantly (Huijsmans/Phouxay 2008). Second, 
data obtained through a long-term ethnographic research project focusing on young migrants from one predominantly ethnic Lao village in lowland Lao PDR (Huijsmans 20IO).

The ILO report forms a component in a regional ILO-sponsored study on recruitment practices finalized in 2008. ${ }^{4}$ Together with a UNIFEM report (Phetsiriseng 2007), this is the only study to date that empirically addresses the phenomenon of migration through Lao employment agencies. The ILO report suffers, however, from important methodological limitations (outlined in Huijsmans/Phouxay 2008: I920). First, due to the timing of the study the sample consisted of early returnees only and does not include any migrants who have completed their two-year contract. Second, the study was conducted in a short period of time, which did not allow building up any form of rapport with the respondents or any followup research. The latter is particularly pressing since cross-border migration into Thailand remains a highly sensitive topic in Lao PDR (see for example Thammavongsa 2006; Pongkhao 2007). The shortcomings of the ILO report are to some extent offset by incorporating material obtained through a long-term ethnographic research project. In that study I succeeded in building a sufficient level of rapport with respondents and conducted multiple interviews between 2007 and 2009 with a purposefully selected set of respondents. Among the respondents were five migrants (four men, one woman) who had migrated through a Lao employment agency. These five were part of the seven total villagers (five men, two women) who had left Baan Naam in the course of 2006 on a two-year contract to Thailand through a Lao employment agency (all through the same agency) and returned in 2008. The men all migrated to an oil palm plantation in southern Thailand (Krabi province) together with thirty-four other male Lao migrant workers. The two women migrated through the same employment agency but were sent to different locations. One was sent to the north-eastern Thai town of Khon Kaen to work in a factory producing fishnets, and the other to central Thailand to work in a pineapple-canning factory. When in Thailand, one of the female migrants and two of the male migrants were interviewed by telephone. This was supplemented with face-to-face in-

4 The Cambodian, Lao, and Thai country reports are synthesized in Chantavanich (2008).

5 Baan Naam is a pseudonym for the research village. Names of respondents presented in this chapter are pseudonyms too. terviews with all but one of the seven migrants upon their return to Baan Naam, and with material obtained from their families.

\subsection{Masculinities and Migration}

For decades, feminist critique of migration theories has expressed concerns about the bias towards the male experience due to the hegemonic construct of 'the migrant' as a male adult breadwinner, which has overgeneralized the experience of women, along with children (Huijsmans 20IIa), as dependants and obliterated the reality of them as agents in migration (Chant I992; Momsen I999; Jolly/Reeves 2005; Donato/Gabaccia/Holdaway/Manalansan IV/Pessar 2006). However, the implicit treatment of "the man" as "the universal, normative subject" (Louie 2002: 5, in: Ford /Lyons 20I2: I) means that in relation to research on men in migration one can also speak of gender blindness since this amounts to a problematic focus "on men as non-gendered humans" (Hibbins/ Pease 2009: 5).

The notion of masculinity is used to gender men. The term refers to "the discourses and [material] practices which indicate that someone is a man, a member of the category of men" (Collinson/Hearn I994: 6). Masculinity, in this sense, is a social construct, which is necessarily plural, hence 'masculinities', as it differs across and within time and space. In addition, masculinities are relational constructs that can only exist in relation to something else like femininity or certain other notions of masculinity (Connell 2005).

Work on masculinities in the context of migration has redressed the gender-blindness that has long characterized the study of men in migration (e.g. Jónsson 2008; Datta/McIlwaine/Herbert/Evans/May/Wills 2009; Donaldson/Hibbins/Howson /Pease 2009; Hoang/Yeoh 20II; Kitiarsa 20I2; McKay/LuceroPrisno III 20I2; Thai 20I2). This body of work has focused mostly on men as migrants (but note: Hoang/ Yeoh 20II), unravelling the interplay between the impact of "global systems of production on the working lives of men" and "the impact of cultural flows on the construction of what it means to be 'a man'" (Ford/ Lyons 20I2: I2). This has yielded research on a wide range of issues including sexual intimacy and migrant men's subjectivity as transnational actors (Kitiarsa 20I2), migrant men's enactment of diverse and conflicting masculinities embedded in the socially constructed spaces comprising the migratory journey (McKay/Lucero-Prisno III 20I2; Thai 20I2), and the 
negotiation and reconstruction of male identities through migration (Datta/Mcllwaine/Herbert/Evans/ May/Wills 2009; Donaldson/Howson 2009: 210).

Work on masculinities and migration has, so far, mostly concentrated on adult men in migration. Relatively little attention has been paid to generational dimensions of masculinities (an important exception includes Jónsson 2008) despite the obvious point that what it means to be a man, as well as becoming a man, is to a great extent shaped by relations of age, whilst migration is also shaped by generational relations (e.g. Haseen/Punpuing 20IO). It is for this reason that I focus in this chapter on a particular generational grouping of men: young unmarried men.

Furthermore, there remains much scope to inform work on masculinities in the context of migration by a gender analysis of policy. Feminist scholars have long pointed out that 'policy' is far from a neutral, genderless activity, and that policymakers, who are often men, are seldom 'neutral' men (Hearn 20II: 159). This would suggest that migration policy is likely to produce a degree of male privilege. At the same time, male privilege in the architecture of migration policy and in the practice of policy does not mean that men are less vulnerable whilst in migration. For example, Donaldson and Howson (2009: 210) have pointed out that whilst it is "usually men who gain more than women from migration", at the same time "it is also men who are more likely to need welfare support, and...who are exposed to greater intolerance, violence and discrimination, in the host country". Even so, hegemonic notions of masculinity frequently leave less space to men than to women in terms of acknowledging vulnerability.

\subsection{Gendered Continuity and Change in the Migration Landscape}

In the years prior to I975 people did not travel a lot like today. People would only occasionally go beyond their village. For example, when I was pen sao (a maturing girl) I never went to Baan Fangthai as young girls do today. However, some other villagers would go to Baan Fangthai in those days (Interview with Mrs Mae Laddavanh in 2008. She was in her forties at the time of interview). ${ }^{6}$

Baan Fangthai, Baan Naam's neighbouring village on the Thai side of the Mekong River, is for many villagers of Baan Naam the gateway to migration further into Thailand. The phrase 'going there' (pai phoun) complemented with a nod towards the Mekong River (and all that lies beyond) was indeed commonly used as a cryptic shorthand for cross-border migration. The above interview excerpt is thus not limited to everyday forms of cross-border mobility, but includes larger migration projects.

Mae Laddavanh makes the striking point that the gendered face of mobility and migration in the middle Mekong valley has transformed dramatically over the past decades. In $\mathrm{Tai}^{7}$ Theravada Buddhist societies mobility has long been part of important rites of passage for young men and contemporary labour migration can thus be seen as a historical continuity in the cultural production of hegemonic masculinity. However, the over-representation of young women in contemporary labour migration in both Thailand and Lao PDR (Mills 1999; MoLSW/Committee for Planning and Cooperation National Statistical Center/ILOIPEC/TICW 2003) presents a sharp break with the very limited mobility experienced by young unmarried women only a generation ago, as commented upon by Mae Laddavanh above.

Kirsch (1985) analyses the masculine and feminine scripts underpinning the gender differences in mobility that were long observable among young people in Tai societies. For young men the practice of pai thiaw (literally: to go around) constituted an "opportunity to wander around, to test themselves in new locales and different styles of life" (Kirsch 1985: 313). Mobility in the past, like labour migration today, was not riskfree and young men were not oblivious to those risks. Fordham (1998: 107) observes in this respect that risktaking behaviour constitutes a key element of hegemonic masculinity in Tai Theravada Buddhist societies because "a man's ability to pull off these sometimes highly dangerous acts [referring to drink-driving,

6 Baan Fangthai is the (pseudonymous) name of the village across the river from Baan Naam on the Thai side of the border and a popular destination for contemporary cross-border wage labour and point of departure for migration further into Thailand by Baan Naam villagers.

7 The term 'Tai' (also 'Tai-Kadai') refers here to the one of the five indigenous South-East Asian language groups. The Tai language group is scattered across South-East Asia (including southern China) and includes 'the national language of Thailand and Laos, as well as the tongues spoken by some upland groups found in those countries' (Ricklefs/Lockhart/Lau/Reyes/AungThwin 20IO: 2). According to the 2009 Lao National Human Development Report, $64.9 \%$ of the total population of Lao PDR belongs to the Tai language group (Souksavath/Acharya 2009: 42). This numerical majority is also the politically and socioculturally dominant group. 
speeding, unsafe sex, etc.] is concrete evidence of his merit, his prowess, and his control over his body and the immediate environment".

The actual experience of vulnerability, understood as the failure to overcome the hardships of migration, greatly undermines one's credibility as a man according to such a hegemonic masculine script (Fordham I998: I06). Furthermore, the emphasis on female vulnerability and the muting of male vulnerability in migration can be understood as an important act of cultural production which serves to maintain gender boundaries in times in which male monopoly over migration as a source of prestige is greatly undermined by the rapid feminization of migration (Mills 1995: 258).

Hegemonic femininity is constructed in terms of motherhood and nurturing, and this has long contributed to limiting women's social and spatial mobility in Tai societies (Keyes 1984; Keyes I986). In the current era of widespread involvement of young women in labour migration the construct of 'dutiful daughter' constitutes a cultural continuity, legitimizing young women's dramatically expanded spatial mobility. Still, young women's involvement in labour migration is met with much greater concern than that of men due to the highly gendered ways in which sexuality is constructed. As Mills (1995: 258) argues: "parents worry about the physical safety of absent sons and daughters alike but usually only daughters are considered at risk of inappropriate sexual activity".

\subsection{The Emergence of a Lao Migration Regime}

In the decades following the establishment of the communist Lao PDR in 1975, migration by Lao nationals to capitalist Thailand was a highly sensitive subject. Official Lao responses boiled down to either ignoring the evidence of irregular Lao migrants working in Thailand, or of condemning it as unpatriotic behaviour concerning only a few isolated individuals. In the r 990 s this position became increasingly untenable mainly because Thai authorities started conducting rounds of registration of unregistered migrant workers on Thai soil (Muntarbhorn 2005: 5). In addition, Lao PDR's entry to the Association of Southeast Asian Nations (ASEAN) in 1997, part and parcel of the Lao state's reorientation towards a politics of regional integration and market economic principles, paved the way for Lao involvement in bilateral and multilateral responses to cross-border migration in the GMS.

The Bangkok Declaration on Irregular Migration of April 1999 forms an important starting point for analysing the emergence of a Lao migration regime. ${ }^{8}$ The Declaration acknowledged cross-border migration as a here-to-stay reality presenting challenges but also opportunities, and requiring "orderly management" based on "concerted efforts of countries concerned, whether bilaterally, regionally or otherwise". The subsequent 2002 Memorandum of Understanding $(\mathrm{MoU})$ on Employment Cooperation between the Royal Thai Government and the Government of Lao PDR can be seen as an expression of the Bangkok Declaration. ${ }^{10}$

In this $\mathrm{MoU}$ the two states agreed upon taking action to realize the following:

I.I Appropriate procedures in employment [of migrant labour]

I.2 Effective deportation and return of migrant workers who have completed the duration of their work permit

I.3 Appropriate labour protection

I.4 Prevention and intervention in illegal border crossing, illegal employment services and illegal employment of migrant workers

(Article I of MoU on Employment Cooperation; in: Muntarbhorn 2005: 6I).

These four key objectives of the MoU illustrate the double-edged sword of the new Lao-Thai approach to migration management and the contradictions between discourses and conditions of 'safety' and 'vulnerability'. The creation of legal channels of migration is legitimized in the name of making migration safer through 'appropriate procedures' and reducing migrant vulnerability through 'appropriate labour protection'. Intertwined with the discursive coupling of the creation of legal channels of migration to migrant safety, point I.4 foreshadows increased efforts to crack down on all forms of migration taking place outside these supposedly safe channels of migration. Given that the majority of Lao migrants migrate in an undocumented manner, and will no doubt continue

8 This Declaration was signed by representatives of the Lao state alongside representatives of twenty-eight other Asia-Pacific countries.

9 With reference to Preamble note (I), (2), and (5), and Declaration note (2) of the Bangkok Declaration on Irregular Migration.

10 Followed in 2005 by an MoU on combating human trafficking. 
doing so in the near future, the condition of migrant vulnerability actually increases for undocumented migrants, thus making migration more unsafe for the majority of Lao cross-border migrants despite discourses of migrant safety.

The problematic interplay between different categories of migration with regard to migrant safety has been commented upon in the Lao and Thai context. From a Thai perspective, Muntarbhorn (2005: iv-v) has argued that Thai migration policies have certainly become more liberal, yet this "more open door policy" is subject to various conditions, most importantly the need "on the part of migrant workers to use open rather than clandestine channels to enter Thailand". Similarly, from a Lao perspective, scholars (e.g. Huijsmans 20Irb; Molland 20I2) have also emphasized that policies addressing irregular migration (especially antitrafficking initiatives) need to be analysed in relation to policies concerning the regularization of migration. It is the interplay between policies addressing seemingly different categories of migration, which are set apart by their opposing relation to constructs of migrant safety, that constitutes the essence of the governmentality, the methods of governance, of Lao-Thai migration.

The establishment of employment agencies constitutes a principal way in which legal channels of migration are expanded. Following Xiang's (2OI2: 5I) work on China, the Lao state too "relies on agents to turn flesh and blood migrants into 'paper migrants', to transform unpredictable individual mobility into legible, aggregate flows, and to hold agents as scapegoats if needed". Lao employment agencies can thus be understood as technologies in the governmentality of Lao-Thai migration. In the Lao context, this notion of governmentality does not take the form of the meticulously orchestrated disciplining in the form of the compulsory pre-departure training as described by Rudnyckyj (2004) in the Indonesian context. ${ }^{11}$ Rather, referring to Lao employment agencies as technologies of governmentality highlights the key role

11 In fact, interviews with representatives from Lao employment agencies conducted in 2007 revealed that in the Lao context such pre-departure training typically lasted two to three hours only and was little more than briefing sessions, often organized at provincial level and conducted by local officials of the Ministry of Labour and Social Welfare. Furthermore, of twenty early returnees interviewed in 2007 who had migrated through Lao employment agencies to Thailand, eight had not received any such pre-departure training/briefing at all (Huijsmans/Phouxay 2008). played by these agencies in the newly emerging Lao migration regime which is making Lao migration into Thailand legible, profitable, and manageable, whilst discursively framing such agencies as a promotion of migrant safety. In addition, the notion of governmentality also highlights the transnational nature of the conduct of conduct in migration management. This allows the analysis of Lao employment agencies to be connected to shifts in transnational migration discourses.

\subsection{Employment Agencies and the Changing Political Economy of Migration}

The creation of legal channels for migration is not something new (Martin 2005), and originally emerged at a time when migration was firmly associated with the construct of the male migrant as the breadwinner. At present, the opening up of legal channels of migration is growing rapidly as a form of migration management. However, unlike when this approach to migration management was first promoted in Western Europe in the years after the Second World War, it is now implemented in a context in which social rights of migrants are being undermined by market forces, and is situated in a migrant landscape that is increasingly recognized as feminizing. ${ }^{12}$ Moreover, in the present-day promotion of the opening up of legal channels of migration, an increasingly important role is attributed to the private sector in recruiting and dispatching migrant labour (for examples in East and South-East Asia see: Rudnyckyj 2004; Anh 2007; Xiang 20I2). This current trend contrasts with earlier approaches in the I950s and I960s in Europe and North America and until several decades later in various socialist states, where it was the state that, on the basis of bilateral agreements, played an active role in dispatching migrant workers (Martin 2005).

This historical shift in the political economy of recruitment of migrants, away from the state and towards the market, can be seen from changes in ILO conventions (Peck/Theodore/Ward 2005: 6). ILO Convention 97 on Migration for Employment (I949)

12 Feminization of migration refers here not only to the growing prevalence of women as migrants, but also to the reduction in, and partiality of forms of, social protection available to female migrants especially compared with what was prevalent under the 'male-breadwinner' model of migration. 
is primarily state-centred and mentions migration through other than "government-sponsored arrangements" only in its annexes. Moreover, it states in Article 2 that:

Each Member for which this Convention is in force undertakes to maintain, or satisfy itself that there is maintained, an adequate and free service to assist migrants for employment, and in particular to provide them with accurate information (emphasis added I949: Article 2).

This Article reflects the ILO's concern, at the time, with for-profit employment agencies which it sought to regulate, if not abolish. With Convention I8I on Private Employment Agencies (I997), the ILO definitely departed from this earlier concern and paved the way for private sector involvement in matching demand and supply in transnational labour markets. This approach has received broad support from influential global players such as the World Bank (e.g. World Bank 2006).

The governments of Lao PDR and Thailand have not ratified any of the ILO conventions mentioned above, yet employment agencies are firmly situated in the newly emerging Lao migration regime. The MoU on Employment Cooperation assigns an important role to "competent authorities" in the management of migration. Later policy documents reveal these "competent authorities" as migration employment agencies. $^{13}$

\subsection{Uncovering Gender in Migration through Lao Employment Agencies}

In the Lao context, it was only in late 2005 that the first batch of Lao migrants was sent to Thailand through employment agencies (Vientiane Times 2005). ${ }^{14}$ Following an initial trial with 30-50 workers, sent out on a one-year contract, subsequent migrant workers were sent out on two-year contracts by a total of nine different employment agencies, including three state-run agencies (Huijsmans/Phouxay 2008). These employment agencies are situated in a highly

13 Note particularly Prime Minister Decree 68/2002 (2002) and Directive of the Minister of Labour and Social Welfare 24I7/MoLSW (2002a).

14 Note however that Phetsiriseng (2007: 43) observes that the State Employment Enterprise has existed since 1995 in Lao PDR, and has over the years recruited a few Lao workers for international migrant work. bureaucratic and gendered regulatory landscape involving two different ministries in both Lao PDR and Thailand, as well as the Lao embassy in Bangkok (for a detailed analysis see: Phetsiriseng 2007; Huijsmans/ Phouxay 2008).

This highly complex structure partly explains why Lao employment agencies lagged considerably behind in meeting the Thai demand for Lao labour. By August 2007 the total request for Lao migrant workers had accumulated to 59,700 while Lao employment agencies had only been able to respond with a total of 6,546 workers (Pongkhao 2007). ${ }^{15}$ Next to the delay caused by the bureaucratic architecture of the recruitment process, the mismatch between Thai demand and Lao supply of formal migrant labour is also caused by the relative expense of this form of migration. Migrants are typically confronted with recruitment fees of I5,000-20,000 Thai Baht (US\$484-645) (Phetsiriseng 2007; Huijsmans/Phouxay 2008: 36). ${ }^{16}$ Paying large sums of money in order to get access to particular forms of employment is fairly common in Lao PDR. ${ }^{17}$ Still, most Lao migrants are unable to meet such expenses prior to migration and these costs are typically deducted from the subsequent migrant's wage. Hence, most migrants find themselves in a situation of debt-bondage since their contracts do not allow them to change employers once in Thailand, yet make them, or their households in Lao PDR, principally responsible for recovering the expenses, as discussed below.

Recruitment practices differ between agencies and include advertising of migrant work over the radio and in printed media, and recruitment through formal channels of command. The latter was the dominant mode of recruitment in Baan Naam, taking the following shape: first, the village head would travel to the district centre to be briefed about migration

15 It should be emphasized that the number of migrants migrating through employment agencies is only a fraction of those thought to have migrated through undocumented channels. The large gap between demand and supply was also caused by the fact that Lao employment agencies were prohibited from sending Lao migrants abroad between January and August 2007 as the Lao state was looking into a range of problems with this form of migration (Huijsmans /Phouxay 2008: 30).

16 This is considerably more expensive than migration through irregular channels (Huijsmans /Phouxay 2008).

17 For example, in $20 \mathrm{I} 2$ young urban Lao would reportedly pay sums of 20 million Lao Kip (US\$2,500) for a job in the booming Vientiane banking sector with a starting salary of about I.5 million Lao Kip (less than US\$200) per month. 
through employment agencies. He, in turn, would announce a 'call for migrant workers' over the village speaker system and invite interested villagers to attend a meeting in the village temple where he would elaborate on further details. After the meeting interested villagers would register with the village head for a particular form of migrant work in Thailand and pay an initial fee to start processing the required documents (e.g. passport). The village head would report these details at the district centre and documents would then be processed. Once passports were ready, the prospective migrants would be invited to the employment agency in Vientiane for a briefing and to sign the contract that tied them to a Thai employer.

Migration policy in practice provides fertile ground for 'mistranslation' of policy. Due to this grapevine structure of communication many Lao migrants enter migration through employment agencies with vague or plainly wrong information, which seriously undermines the migrant safety these channels of migration are meant to contribute to. In addition, by bringing recruitment into the formal domain it becomes associated with masculine institutions. This shift in the field of recruitment affects, even at village level, potential migrants in a gendered fashion. The five young migrants interviewed all claimed it was they who took the initiative for migration through an employment agency. Yet only the four young men attended the meetings at the village temple in person. Nalintone, the only female migrant interviewed, did not attend these meetings in person. In her case one of her parents attended the concerned meetings. This no doubt explains why Nalintone was most articulate about the lack of information she had received prior to migration. For this reason she described migration through Lao employment agencies as 'pai dao' (go guessingly).

\subsubsection{Gender and the Construction of Legitimate Migrant Labour}

Whereas in the recent past cross-border migration into Thailand was framed by the Lao state as undermining national development, the Prime Minister's Decree No. 68/2002 (2002) reframes it as a positive contribution to national development. It does so by emphasizing its potential for "upgrad[ing] the skills of Lao citizens" in terms of "knowledge" and "technicalprofessional" skills (ibid.: Article I). Policy note $30 \mathrm{II}$ of the Minister of Labour and Social Welfare of the Lao PDR (2007) adds a further range of migration bonuses, including its supposedly poverty-reducing im- pact and a reduction of national unemployment; and through the skill-upgrading envisioned taking place through migration the returnees are considered more capable of participating in Lao national development. This justification of the Lao state's new position on the issue of cross-border movement into Thailand is underpinned by a discourse of development as modernization (Vijayan 2002). Vijayan argues, on the basis of the Indian case, that this development discourse constitutes a "silent privileging of the masculine" (Vijayan 2002: 34).

This gendered justification of the state's promotion of cross-border labour migration maps onto a gender-segregated migrant labour market, gender differences in the valuing of forms of work, and notable gender differences in the experience of being young. This becomes evident from the list composed by the Lao state that employment agencies need to abide by. It is at this level that the construction of legitimate cross-border migration and migrants to Thailand starts translating into highly gendered realities. First, potential migrants need to meet a series of minimum requirements. This includes minimum age requirements (I8 years), completion of at least primary education, good health, and good citizenship (Ministry of Labour and Social Welfare 2002a: Article 3). Seemingly gender-neutral, these requirements play out in a gendered social reality and, thereby, come to reinforce gender inequalities.

With regard to the education requirement, for 2004-2005 a 44.2 per cent national primary school completion rate was reported. The main variation within this national average is by province (correlating with ethnicity). However, for virtually all provinces the average number of years of schooling differs between men and women, with the male population, on average, having spent more years in education than their female counterparts (Souksavath/Acharya 2009: 227). These gender differences in educational requirements were also observed in the migrant population surveyed by the 2003 Labour Migration Survey. Although on average the migrant population was found to be educated to a slightly higher level than the total population, the share of female migrants who had not completed primary education was, at I2.5 per cent, a fraction higher than the corresponding share (9 per cent) among the male migrants (ILO 2007: 24).

The minimum age requirement also plays out in a gendered manner. As observed above, several studies (e.g. MoLSW/Committee for Planning and Cooperation National Statistical Center ILO-IPEC/TICW 2003; Huijsmans 20IO) have shown that in the Lao 
context, migration is shaped by the combined working of gender and generation. At the aggregate level Lao migration data show some gender disparity, yet this disparity becomes far more pronounced if a generational dimension is added. The 2003 Labour Migration Survey data illustrate this point most clearly (MoLSW/ Committee for Planning and Cooperation National Statistical Center/ILO-IPEC/TICW 2003). Based on a survey using statistically representative methods employed in three Lao provinces, and covering 5,966 households, a total outmigration rate of 6.9 per cent was found, with the vast majority of observations (over 80 per cent) concerning cross-border migration to Thailand. The total cross-border migrant population breaks down as 4I per cent male migrants and 59 per cent female migrants. However, gendered patterns are far more pronounced if we concentrate on migrants below I8 years of age, comprising 2I.5 per cent of the total migrant population. ${ }^{18}$ This sub-sample is disproportionally female (over 70 per cent), reflecting the fact that 25.4 per cent of all female crossborder migrants were younger than I8 years of age, whereas this figure is only 15.6 per cent for all male cross-border migrants.

The discussion above illustrates that seemingly gender-neutral requirements such as minimum age and minimum educational requirements operate in gendered terrains and thereby come to reinforce gender inequalities, as potential male migrants are, on average, more likely to meet these requirements than potential female migrants. In addition to the gendered working of requirements imposed at the level of the individual, gender can also be observed in relation to the categories of migrant work prohibited from recruitment. In a Ministerial Regulation (Labour and Social Welfare) issued in December 2002 by the Lao PDR (2002b), three categories of work were prohibited from recruitment. These were:

1. plain jobs that do not require the assistance of mechanical machines in the workplace, do not develop skill levels, and do not provide technical knowledge (e.g. cleaning, sweeping, portering, digging canals/fishponds);

18 This concerns cross-border migration predominantly (over 80 per cent), and mostly older children. Note further that the migration survey does not explain whether the age concerned was the first age of migration or the current age of migration. Neither is the study clear about the precise definition of migration that was employed (e.g. in terms of duration).
2. jobs that are contradictory to customs and traditions, culture, or law (e.g. prostitution, pimp, spy, terrorist, drug dealer, selling sexual equipment, nude shows);

3. jobs that are dangerous to the health and life of the workers (e.g. exposure to chemicals, radiation, explosive substances, open-sea fishing in small boats, catching wild animals such as tigers, lions, or crocodiles).

(Adapted from Phetsiriseng 2007: 56-57.)

We limit ourselves here to the first category of 'plain jobs' and focus on domestic work in particular. ${ }^{19}$

Due to its largely undocumented nature, the magnitude and sectoral distribution of Lao migrant work in Thailand is only known by approximation. Yet Thai data on the application for work permits by eligible Lao migrant workers following the Thai 2004 round of registration is instructive here, despite its limitations (Table I9.I).

Table 19.1: Work permits issued to Lao workers already in Thailand by mid-December 2004 (following the 2004 round of registration), by sector. Source: Adapted from World Bank (2006: 56).

\begin{tabular}{|l|c|c|}
\hline Type of work & $\begin{array}{c}\text { Number of } \\
\text { Permits Issued }\end{array}$ & Per cent \\
\hline On fishing boats & 2,634 & 2.7 \\
\hline Fish processing & 1,013 & 1.0 \\
\hline Agriculture & 16,795 & 16.9 \\
\hline Construction & 8,442 & 8.5 \\
\hline Domestic service & 31,449 & 31.7 \\
\hline Other & 39,019 & 39.3 \\
\hline Total & 99,352 & 100 \\
\hline
\end{tabular}

Table I9.I shows that domestic work is by far the single largest occupation of Lao migrant workers in Thailand. Since Lao migrant domestics are predominantly female (see e.g. Muttarak 2004; Phetsiriseng 2007: 78), the gendered impact of omitting 'plain work' from recruitment is significant, and far more pronounced than the exclusion of, for example, jobs in the 'dangerous to health' category such as open-sea fishing, which will affect Lao men primarily but in much smaller numbers.

19 However, a similar argument could be made for migrant sex work, which is also done mostly by women and excluded from these supposedly safe channels of migration. 
Constructing domestic work, cleaning work, etc., as 'plain work' that does not contribute to the development of any skills makes it incompatible with the highly gendered legitimization of cross-border migrant work mentioned above: skills upgrading of the Lao workforce with the ultimate goal of realizing an implicitly masculine project of development as modernization. This framing of domestic work indeed misrecognizes the very real skills this work requires at a professional and interpersonal level. Moreover, the absence of women's domestic and cleaning work from legitimate migrant labour can also be explained by efforts to preserve the dominant feminine value of 'mother-nurturer', which underpins the official discourse on women's role in Lao national development as wives, mothers, and preservers of traditional culture (e.g. Sangsomboun 2008). ${ }^{20}$ Acknowledging the reality of the earnings from Lao women's migrant domestic work sustaining numerous livelihoods and thus being an important foundation of Lao national development would require a profound reworking of this dominant feminine ideal. Lastly, omitting Lao women's domestic work from legitimate forms of migrant work also needs to be appreciated against a lingering sense of inferiority on the part of the Lao in Lao-Thai relations (Ngaosyvathn /Ngaosyvathn I994; Theeravit/Semyaem 2002; Pholsena/Banomyong 2006: 60-6I). Lao women cleaning the houses of Thai nationals can be viewed as the very articulation of a masculine sense of Lao inferiority which the Lao state seeks to overcome, and this sheds yet another light on the exclusion of domestic work from legitimate migrant work.

20 At the first Women's Congress of the Members of the Women's Association Central Committee of Lao PDR in 1984 the motto of "three goods and two duties" was coined. The three goods include being a good citizen, a good mother, and a good wife, and the two duties include a duty of national defence (socialist construction) and women's emancipation (Ngaosyvathn 1995: I05-I07; Ireson-Doolittle/Moreno-Black 2004: 27). Such mottos have never been applied to men, who were simply seen as already 'good' and 'dutiful' (Ngaosyvathn I995: 107). With the socialist rhetoric quickly fading and a widespread return to 'traditional' Lao values, being a 'good citizen' is in relation to Lao women increasingly translated into preserving ethnic Lao traditional culture such as wearing traditional dress, traditional hairstyles, etc.

\subsubsection{Gender and Generation in Entering Migration through Employment Agencies}

In a similar way to the limitations imposed on potential migrants and migrant work, the high costs attached to migration through employment agencies do not play out in a socially undifferentiated manner. Most importantly, Baan Naam data illustrate that this ensures that only those from relatively better-off families would even consider becoming involved in this form of migration (Huijsmans 20I0: I78). Next, it also ensures that only one household member at a time can become involved in this form of migration. ${ }^{21}$ In the demographic context of fairly large household sizes, it is then of interest to observe how entry into employment agencies is shaped by relations of gender and generation.

Among the seven migrants from Baan Naam who had gone through an employment agency to Thailand all but one migrant were 'dependants' at the time of migration in the sense that they had not yet established their own households. This means that despite the fact that these young migrants claimed it was they who initiated the decision to migrate, such claims should not be read as the unconstrained exercising of young people's agency. Importantly, as dependants, these sons and daughters lack the collateral to sign up for migration through employment agencies. Hence, at the end of the day it is their parents who act as gatekeepers, which means that migration decisionmaking is here shaped by generational relations. Research in Baan Naam showed that this dimension even gained contractual status as employment agencies would enter separate contracts with the head of household of the migrants concerned, making the Lao household responsible for recovering the expenses associated with recruitment should the migrant concerned fail to do so him/herself (Huijsmans 20IO).

The two most comprehensive studies on migration through employment agencies (Phetsiriseng 2007; Huijsmans/Phouxay 2008) fail to present statistical data on recruitment through agencies in a gender-disaggregated form. Doneys (20II: 56) reports, however, that in 2008 most Lao migrants who had entered Thailand through employment agencies were

21 The one exception included a household in which both the father and the second-born (son) signed up for migration, leaving behind the mother and three children. 
male (62 per cent). This pattern is indeed reflected at the micro-scale of Baan Naam. ${ }^{22}$ Importantly, this gender pattern of migration through employment agencies contrasts with the overall pattern of crossborder migration of Lao nationals into Thailand in which men constitute a minority (4I per cent, as stated above). Part of the explanation of this divergence may be found in the gendered construction of legitimate migrant work discussed above which produces a degree of male privilege.

Male privilege is further aggravated by the intersection of relations of gender and generation at the scale of the household. Three factors are at stake here. First, women tend to marry at an earlier age than men. Because it is primarily unmarried young people that become involved in migration and since there is a minimum age of recruitment of I8 years, the supply of potential male migrants outstrips that of potential female migrants. Second, the daily presence of daughters is, in general, of greater value to rural households than the daily presence of sons. Daughters are not only involved in a far greater range of everyday forms of work that are of significant importance for the production and reproduction of rural households, but parents are, in general, also more successful in directing their daughters' labour towards the household economy than that of their sons (Huijsmans 20IO: I4I). Hence, parents may be keener to approve of, and finance, the absence of a son than a daughter. In relation to the above, and thirdly, whereas daughters' involvement in migration is often met with parental concern (Rigg 2005: 150), in relation to sons it is local idleness that worries parents. Motivating sons to become involved in migration through employment agencies should thus not only be interpreted from an economic perspective, but also as a gendered form of parental discipline. Stemming from a hegemonic notion of masculinity which values risk-taking behaviour (Fordham I998), sons' idleness is associated with drinking, getting into fights, and impregnating girls, whereas migrant work through formal channels is seen as mitigating these possible troubles. Moreover, encouraging sons into two-year migrant contracts may also constitute a parental strategy of postponing possible marriages of their sons and the financial implications of this. ${ }^{23}$

22 Note that one of the two young women who migrated through an employment agency comes from a household with daughters only, rendering the gender question largely irrelevant.
I was afraid that if he were to stay in Baan Naam he would find a girl and get married. Yet, right now we don't have the money for a wedding [their first-born [son] had just married]. Also, he should first earn money himself before getting married, that's why I think it is good that he went again (Notes from interview with a mother whose second-born (son) was about to migrate for a second time through an employment agency on a two-year contract to Thailand; 2008, Baan Naam).

\subsection{Masculinity and the Limitations of Male Privilege}

The previous sections have shown that the gendered construction of the functioning of Lao employment agencies produces male privilege; men are more likely to become involved in this form of migration than women. This is potentially in tension with the policy rhetoric that presents migration through legal channels as contributing to migrant safety based on a dominant discourse of female migrants' vulnerability which is widespread in the activist and academic literature but also clearly identifiable in everyday village life:

It would have been different. Girls would have listened and stayed. For example, I also wouldn't want my younger sister to go and work elsewhere because for girls it is more dangerous than for men. Men look stronger than women and are, therefore, safer. Also when we see the news, it is always girls to which bad things happen. Therefore, I also don't want my younger sister to go (Excerpt from interview with Jonnie (male, 2I years), Baan Naam, 2009, about why he and not his sister became involved in migration through employment agencies).

Jonnie's remark reflects a widespread perception about female migrants' vulnerability, and in Jonnie's case this remained 'fact' even though his own experience stands out as a case in point of male vulnerability, as is discussed in more detail below. The governmentality of the Lao migration regime, which may be summarized as bringing about a 'conduct of conduct' that discourages potential migrants from migrating through irregular channels by emphasizing the associated 'risks' and stimulating migrating in a documented fashion through the promotion of 'safety', can be assessed as relatively successful based on the observation that security considerations indeed emerged as an important motivation for migrants to opt for employment agencies despite the considerable costs $(\mathrm{Hu}-$

23 Note that in the matrilocal ethnic Lao context bridegrooms or their family pay a bride price. 
ijsmans/Phouxay 2008). Importantly, this governmentality of migration has also shifted the cultural styles of hegemonic notions of masculinity. While we have earlier observed that risk-taking behaviour constitutes an important element in hegemonic forms of masculinity among Tai men, so does a "preoccupation with protection from danger" (Tambiah 1984, in: Fordham I998: 107). Whereas in the past this concern with protection from danger manifested itself primarily in the form of the accumulation of amulets, performance of rituals, and the search for blessings (e.g. Mills 1995; Fordham 1998), statements like the one below suggest that performing a modern form of citizenship, by migrating through state-related institutions in a documented manner, has become part of the cultural style of seeking protection from danger among young men.

I went through an agency because I thought that if something would happen the agency would take care of it. Also, this is a comfortable way of going since all the documents are in order. This was important since I was a bit afraid to go abroad for such a long time because I had not done so before (Notes from interview with Som (male, mid-twenties) upon return from two years in Thailand; Baan Naam, 2009).

These young men paid large sums of money or became indebted to the employment agency as a means to secure a certain degree of protection from danger when engaging in an activity (cross-border migration into the deep South of Thailand) they clearly understood as risky. The question remains, however, whether migration through Lao employment agencies as a means to protect oneself from danger actually contributes to making migration safer in a material sense, or should indeed be viewed as a cultural style? A first point of concern in addressing this question is whether migrants migrating through employment agencies actually know what they are stepping into. A survey among twenty migrants showed that virtually all had received information about the nature of work, wages, working hours, health care, and termination of employment prior to migration, which, indeed, compared favourably with migrants who had migrated through informal channels (Huijsmans/ Phouxay 2008: 40). However, when asked how predeparture and contractual information compared with the actual reality at the migration destination a significant discrepancy was observed, as illustrated in Table 19.2.

The data presented in Table 19.2 was collected among early returnees and as observed in the methodology section contains an important element of bias.
Table 19.2: Areas in which the reality of migration differed from the pre-departure information. Source: Adapted from Huijsmans and Phouxay (2008: 41).

\begin{tabular}{|l|c|}
\hline Category & Formal recruits $(\mathbf{n = 2 0})$ \\
\hline nature of work & 15 \\
\hline salary & 16 \\
\hline working hours & 14 \\
\hline overtime & 6 \\
\hline rest days & 9 \\
\hline living conditions & 15 \\
\hline risks and dangers & 10 \\
\hline
\end{tabular}

However, the qualitative data from Baan Naam confirms the above picture:

Research Assistant: Before you went, did you know exactly about the kind of work you were to do?

Jonnie: When the village head announced the possibility of working in Thailand over the village speaker system, he said there were two types of jobs: work in a fish canning factory and work in a pineapple canning factory... we were preparing to go there [to one of the factories] and our passports were processed. But then the factories did no longer need workers, and a palm oil plantation needed workers urgently, so we went there but we had no idea what we would be doing there.

RA: Did you go to all the meetings?

Jonnie: Yes I went to all the meetings, but during these meetings they didn't talk about the palm oil plantations, only about the pineapple and fish canning factory. It was only in the very end that we heard a little bit about plantation work...I wanted to work in one of the factories... but in the end this work was not available. So I went to the palm oil plantations...I went [there] because my passport was already issued and I was indebted for I5,000 Baht with the employment agency and had spent about 5,000 Baht myself in the district level to prepare documents (Excerpt from interview with Jonnie (male 2I years), upon return in Baan Naam, 2009).

Since passports were already issued and valid for three years only, Jonnie and the other young men from Baan Naam felt they could not take their chances. Rejecting a migrant opportunity without knowing when and what would come up was playing with their chances which could lead to a situation in which their passport would run out before having completed a standard two-year contract. For this reason they were ready to accept entirely different work from the sort of migrant work they had initially registered for without knowing much about what this work entailed. 
This indeed constitutes another form of 'mistranslation' of policy.

Next to pre-departure information about the type and nature of work, information about prospective salaries was also unclear. Salaries were typically presented as a range in the migrant contracts. Yet upon arrival the migrants were soon to discover that their actual salaries rarely went beyond the low end of this range. This practice left Som, a young man in his midtwenties, to observe ironically that "everything they [employment agencies] had said was true", meaning that the agency had emphasized the most rosy reading of the contract, without highlighting the fact that there were no guarantees that these conditions would be met.

Consequently, salaries and conditions of work quickly became a main point of contestation for the Baan Naam men who had migrated to the southern Thai palm oil plantations. Once at the plantation the Lao workers found themselves allocated lowly paid tasks like weeding and applying pesticides and excluded from better-paying types of work like harvesting the palms, which were reserved for Thai labour teams. ${ }^{24}$ Following the pre-departure recommendations of the Lao employment agency, the men got in touch with the agency in order to have their concerns addressed:

Before we left we were told to get in touch with the employment agency in case of any problems. And so we did, but the employment company did not like it when I called them and they did nothing with our complaints. Whenever we called, the Lao employment company would just get in touch with a Thai middleman. The middleman would then say that the Lao workers were just too lazy. You know, the Thai middlemen and the Lao employment agency eat and drink beer together, so they believe each other no matter what we say. Also, the Lao employment agency got their money already from the palm plantation so they didn't care anymore. (Notes from interview with Sukan's father in Baan Naam, 2008. He was the only adult in a group of five male workers from Baan Naam, including his second-born son (Sukan), working at the oil palm plantation. As the only adult he acted as the group leader.)

24 Work in the palm oil plantations is at piece rate. A main difference between harvesting the palms and work like weeding and applying chemicals was that the former allowed workers to put in many hours of work with the possibility of earning much higher wages than they could earn by weeding and applying chemicals-which was seen as a single task of fixed magnitude and was often completed in less than a working day.
Over time, two of the young Lao men managed to get out of these lowly paid tasks. Based on their physical strength, they were asked to join a Thai work team on the plantation, which allowed them to enter the more profitable work of harvesting palms. Bodily performance contributes here to the constitution of a hegemonic notion of masculinity, which makes, however, gender vulnerable on two accounts. First, it immediately renders gender vulnerable for the five men whose bodily performance fell short, particularly since the alternative strategies for improving their fate (repeatedly bringing up their complaints) proved futile. Second, the hard labour of harvesting palm trees does not contribute to skill formation. Hence, the immediate improvement achieved through the bodily performance of physical strength is likely to render these men's gender vulnerable in the long run because labour under 'the regime of profit uses up the workers' bodies, through fatigue, injury and mechanical wear and tear', a process which is here not offset by the growth of skill (Connell 2005: 55).

The Lao migrants who have migrated through employment agencies are, by contract, tied to a specific employer, and their indebtedness to the Lao employment agency means that these migrant workers have little other choice than to stick to their job despite problems remaining unresolved. It is only when the worst comes to the worst that migrants who had migrated through employment agencies would resort to quitting without notice. $^{25}$

After about one and a half year into his contract Jonnie fell ill, which he believed was due to his daily work with pesticides in the palm oil plantation. After a period of tiredness and dizziness he could at some point no longer stand and walk and was hospitalized for eight days. After being discharged from the hospital his fellow workers from Baan Naam advised him to quit, as they feared continuing the work might kill Jonnie. Since Jonnie had paid off his debts he decided to quit. Without bothering to ask for his passport (which was kept by his employer) he travelled independently and in an undocumented fashion back to Lao PDR (Notes from interviews with Jonnie; Baan Naam, 2009).

Quitting without notice and leaving one's passport and documented status behind constituted in this case a form of dealing with the migrant vulnerability created by the conditions of migrating through em-

25 Free transport back to Lao PDR at the end of the contract is another motivation for Lao migrants to try to complete their contracts rather than quit prematurely. 
ployment agencies. Ironically, even this strategy, which is frequently employed by undocumented Lao migrants in Thailand as an act of agency in response to dissatisfaction with their migrant work conditions (Huijsmans 20IO), is more risky for documented migrants than for undocumented migrants as the former leave a traceable identity behind.

\subsection{Conclusion}

In this chapter I have shown that notions of risk and safety feature prominently in discourses underpinning transformations in the architecture of migration regimes. In the Lao-Thai case presented in this chapter, migration through irregular channels is constructed as risky and dangerous and this provides an important justification for interventions aimed at preventing, discouraging, and even criminalizing such forms of migration. At the same time, the creation of legal channels of migration is presented and promoted as making migration 'safe'. Employment agencies are key actors in the newly established formal channels of migration and are assigned the 'duty' of safeguarding migrant safety by ensuring protection of migrant workers in accordance with relevant laws and regulations (Prime Minister's Office, Lao PDR 2002).

Concerns about migrant safety are often highly gendered, revolving around female migrants' vulnerability, whereas hardship experienced by male migrants is only seldom problematized due to hegemonic notions of masculinity. Despite such gendered constructs of vulnerability, interventions promoted as improving migrant safety are typically presented as gender-neutral. This is especially true for employment agencies, which are presented as making migration safer and are envisioned doing so in a gender-neutral fashion.

I have, however, shown employment agencies to be distinctly gendered. Firstly, these agencies are embedded in the gendered terrain of the emerging Lao migration regime. The latter is underpinned by a discursive re-appreciation of cross-border migration as

\section{References}

Anh, Dang Nguyen, 2007: "Labour Export from Viet Nam: Issues of policy and practice”. 8th International Conference of Asia Pacific Migration. Fuzhou, China, 25-29 May 2007.

Chant, Sylvia, Ed., I992: Gender and Migration in Developing Countries. New York, (London: Belhaven Press). something that is conducive to the implicit masculine discourse of development as modernization embraced by the Lao state. I have argued that hegemonic notions of masculinity and femininity underpin the construct of legitimate cross-border migrant work, which effectively excludes large parts of the Lao female migrant labour population from these supposedly safe channels of migration. Furthermore, the seemingly gender-neutral selection criteria applied by employment agencies produce significant degrees of male privilege in accessing safe migration because they inevitably play out in the highly gendered social terrain of contemporary Lao society.

Whilst young Lao men may be privileged in accessing these supposedly safe forms of migration, I have argued that the male privilege is highly limited. In fact, the conditions of migration through employment agencies may well contribute to an increase in migrant vulnerability, as the case of Jonnie illustrated. Furthermore, under the highly constraining conditions of contractual labour migration young men typically had to rely on the bodily performance of sheer physical labour power in order to improve their individual situation. I have argued, however, that such bodily performance renders gender vulnerable regardless of whether male migrants are able to contribute to this dimension of the constitution of a hegemonic notion of masculinity.

Lastly, I have argued that evaluating young Lao men's motivations to migrate through these very costly employment agencies in purely material terms loses sight of how it may rather constitute a modern version of a cultural style of hegemonic masculinity. Acknowledging young men's migration through employment agencies as the seeking of protection from danger through the performance of a modern form of citizenship explains, for example, the paradoxical observation that the young men from Baan Naam (and none of the young women) decided, with the exception of Jonnie, to remigrate through the very channels of migration that had already failed them once.

Chantavanich, Supang, 2008: The Mekong Challenge: An honest broker-improving cross-border recruitment practices for the benefit of government, workers and employers (Bangkok: International Labour Office-ILO, Mekong Sub-Regional Project to Combat Trafficking in Women and Children, International Programme on the Elimination of Child Labour). 
Collinson, David; Hearn, Jeff, I994: "Naming Men as Men: Implications for work, organization and management", in: Gender, Work and Organization, I,I: 2-I9.

Connell, R.W., 2005: Masculinities (2nd edition). (Cambridge: Polity Press).

Datta, Kavita; Mcllwaine, Cathy; Herbert, Joanna; Evans, Yara; May, Jon; Wills, Jane, 2009: "Men on the Move: Narratives of migration and work among low-paid migrant men in London", in: Social \& Cultural Geography, Io,8: 853-873.

David, Fiona; Gallagher, Anne; Holmes, Paul; Moskowitz, Albert, 20II: Progress Report on Criminal Justice Responses to Trafficking in Persons in the ASEAN Region (Jakarta: Association of Southeast Asian Nations (ASEAN)).

Donaldson, Mike; Hibbins, Raymond; Howson, Richard; Pease, Bob (Eds.), 2009: Migrant Men: Critical studies of masculinities and the migration experience (New York, Oxon: Routledge).

Donaldson, Mike; Howson, Richard, 2009: "Men, Migration and Hegemonic Masculinity", in: Donaldson, Mike; Hibbins, Raymond; Howson, Richard; Pease, Bob (Eds.): Migrant Men: Critical studies of masculinities and the migration experience. (New York, Oxon: Routledge): 210-2I7.

Donato, Katharine M.; Gabaccia, Donna; Holdaway, Jennifer; Manalansan IV, Martin; Pessar, Patricia R., 2006: "A Glass Half Full? Gender in migration studies", in: International Migration Review, 40,I: 3-26.

Doneys, Philippe, 20II: "En-gendering Insecurities: The case of the migration policy regime in Thailand", in: The International Journal of Social Quality, I,2: 50-65.

Dottridge, Mike, 2006: Action to Prevent Child Trafficking in South Eastern Europe: A preliminary assessment (Lausanne, Geneva: Terre des Hommes, UNICEF).

Ford, Michele; Lyons, Lenore, 20I2: "Introduction", in: Ford, Michele; Lyons, Lenore (Eds.): Men and Masculinities in Southeast Asia (London, New York: Routledge): I-I9.

Fordham, Graham, 1998: "Northern Thai Male Culture and the Assessment of HIV Risk: Toward a new approach", in: Crossroads: An interdisciplinary journal of Southeast Asian studies, I2,I: 77-I64.

Gaetano, Arianne M.; Yeoh, Brenda S.A., 20IO: "Introduction to the Special Issue on Women and Migration in Globalizing Asia: Gendered experiences, agency, and activism”, in: International Migration, 48,6: I-I2.

Haseen, Fariha; Punpuing, Sureeporn, 20I0: "Impact of Ageing on Migration in Asia”, in: Hofmeister, Wilhelm (Ed.): Ageing and Politics: Consequences for Asia and Europe (Singapore: Konrad-Adenauer-Stiftung): 15-35.

Hearn, Jeff, 20II: "Gender Regimes Changing Men or Men Changing Gender Regimes? Challenges for national and transnational social policy, gender equality and organizing with men”, in: Cornwall, Andrea; Edström, Jerker; Greig, Alan, (Eds.): Men and Develoment: Politicizing masculinities (London, New York: Zed Books): I55-I69.
Hibbins, Raymond; Pease, Bob, 2009: "Men and Masculinities on the Move", in: Donaldson, Mike; Hibbins, Raymond; Howson, Richard; Pease, Bob (Eds.): Migrant Men: Critical studies of masculinities and the migration experience (New York, Oxon: Routledge): I-20.

Hoang, Lan Anh; Yeoh, Brenda S.A., 20II: "Breadwinning Wives and 'Left-behind' Husbands: Men and masculinities in the Vietnamese transnational family", in: Gender \& Society, 25,6: 717-739.

Huijsmans, Roy B.C., 20IO: "Migrating Children, Households, and the Post-Socialist State: An ethnographic study of migration and non-migration by children and youth in an ethnic Lao village" (Unpublished PhD thesis, Durham, UK: Durham University, Department of Geography).

Huijsmans, Roy, 20IIa: "Child Migration and Questions of Agency”, in: Development \& Change, 42,5: I307-I32I.

Huijsmans, Roy, 2orrb: "The Theatre of Human Trafficking: A global discourse on Lao stages", in: International Journal of Social Quality, I,2: 66-84.

Huijsmans, Roy; Phouxay, Kabmanivanh, 2008: "Whether you go illegally or legally in the end it's the same, you're cheated". A study of formal and informal recruitment practices of Lao workers migrating to Thailand (Vientiane: International Labour Organisation, National University of Laos).

ILO (International Labour Organization), I949: Convention Concerning Migration for Employment (1949 Revised), C97. 22-OI-I952.

ILO, 2003a: Legal Labour Migration and Labour Markets: Alternatives to substitute for trafficking in children and women'. Technical Intervention Area Summary Note, TIA-I (Bangkok: Mekong Sub-regional Project to Combat Trafficking in Women and Children, International Programme on the Elimination of Child Labour, International Labour Organization).

ILO, I2003b: Trafficking in Human Beings: New approaches to combating the problem (Geneva: International Labour Office, Special Action Programme to Combat Forced Labour).

ILO, 2007: The Mekong Challenge - Winding Roads: Young migrants from LaO PDR and their vulnerability to human trafficking. An analysis of the 2003 Lao PDR migration survey with a new introduction and foreword (Bangkok: International Labour Office, Mekong Sub-Regional Project to Combat Trafficking in Children and Women, International Programme on the Elimination of Child Labour).

ILO, 2008: Meeting the Challenge: Proven practices for human trafficking prevention in the Greater Mekong Sub-region (Bangkok: International Labour Organization, Mekong Sub-regional Project to Combat Trafficking in Women and Children, International Project on the Elimination of Child Labour).

Ireson-Doolittle, Carol; Moreno-Black, Geraldine, 2004: The Lao: Gender, power, and livelihood (Boulder, Colorado: Westview Press). 
Jolly, Susie; Reeves, Hazel, 2005: Gender and Migration: Overview Report (Brighton: IDS-BRIDGE).

Jónsson, Gunvor, 2008: Migration Aspirations and Immobility in a Malian Soninke Village. Working Paper, No. Io (Oxford: University of Oxford, James Martin 2Ist Century School, International Migration Institute [IMI]).

Keyes, Charles F, 1984: "Mother or Mistress but Never a Monk: Buddhist notions of female gender in rural Thailand", in: American Ethnologist, II,2: 223-24I.

Keyes, Charles, F, I986: "Ambiguous Gender: Male initiation in a Northern Thai Buddhist society", in: Walker Bynum, Caroline; Richman, Paula; Harrell, Stevan (Eds.) Gender and Religion: On the complexity of symbols (New York: Beacon Press): 66-96.

Kirsch, A. Thomas, 1985: "Text and Culture: Buddhist sex roles/culture of gender revisited”, in: American Ethnologist, I2,2: 302-320.

Kitiarsa, Pattana, 20I2: "Masculine Intent and Migrant Manhood: Thai workmen talking sex", in: Ford, Michele; Lyons, Lenore (Eds.) Men and Masculinities in Southeast Asia (London, New York: Routledge): 38-55.

Louie, K., 2002: Theorizing Chinese masculinity: Society and gender in China (Cambridge: Cambridge University Press).

Martin, Philip, 2005: Merchants of Labor: Agents of the evolving migration infrastructure. Discussion Paper, DP/I58/2005 (Geneva: International Labor Organization, International Institute for Labor Studies).

McKay, Steven; Lucero-Prisno III, Don Eliseo, 20I2: "Masculinities Afloat: Filipino seafarers and the situational performance of manhood", in: Ford, Michele; Lyons, Lenore (Eds.) Men and Masculinities in Southeast Asia (London, New York: Routledge): 20-37.

Mills, Mary Beth, 1995: "Attack of the Widow Ghosts: Gender, death, and modernity in Northeast Thailand", in: Ong, Aihwa; Peletz, Michael G (Eds.): Bewitching Women, Pious Men: Gender and body politics in Southeast Asia (Berkeley, Los Angeles, London: University of California Press): 244-273.

Mills, Mary Beth, 1999: Thai Women in the Global Labor Force: Consuming desires, contested selves (New Brunswick, New Jersey, London: Rutgers University Press).

Ministry of Labour and Social Welfare, Lao PDR, 2002a: Directive of the Minister of Labour and Social Welfare on the Implementation of the Prime Minister's Decree on Sending Lao Workers to Work Abroad (unofficial translation), 24I7/MoLSW 29 July 2002.

Ministry of Labour and Social Welfare, Lao PDR, 2002b: Regulation of the Minister of Labour and Social Welfare on the Types of Jobs Prohibited for Sending Lao Workers to Work Abroad (unofficial translation), 3824/ MoLSW I9 December 2002.

Minister of Labour and Social Welfare, Lao PDR, 2007: Continuation of sending of Lao workers abroad (unofficial translation), 30II/MoLSW, 8 August 2007. (Policy Note 30II/2007)
Molland, Sverre, 20I2: "Safe Migration, Dilettante Brokers and the Appropriation of Legality: Lao-Thai 'trafficking' in the context of regulating labour migration", in: Pacific Affairs, 85,I: II7-I36.

MoLSW, Committee for Planning and Cooperation National Statistical Center and ILO-IPEC/TICW, 2003: Labour Migration Survey in Khammuane, Savannakhet and Champasack 2003 (Vientiane: Ministry of Labour and Social Welfare, Department of Labour [Lao PDR], Committee for Planning and Co-operation of the National Statistical Center, International Labour Organisation-IPEC/TICW [International Programme on the Elimination of Child Labour/Project to combat Trafficking in Children and Women]).

Momsen, Janet Henshall (Ed.), I999: Gender, Migration and Domestic Service (London, New York: Routledge).

Muntarbhorn, Vitit, 2005: The Mekong Challenge. Employment and Protection of Migrant Workers in Thailand: National Laws/Practices versus International Labour Standards? (Bangkok: International Labour Organization).

Muttarak, Raya, 2004: "Domestic Service in Thailand: Reflection of conflicts in gender, class and ethnicity", in: Journal of Southeast Asian Studies, 35,3: 503-529.

Ngaosyvathn, Mayouri, 21995: Lao Women Yesterday and Today (Vientiane: Lao State Printing Enterprise).

Ngaosyvathn, Mayouri; Ngaosyvathn, Pheuiphanh, 1994: Kith and Kin Politics: The relationship between Laos and Thailand (Manila: Journal of Contemporary Asia Publishers).

Peck, Jamie; Theodore, Nik; Ward, Kevin, 2005: "Constructing Markets for Temporary Labour: Employment liberalization and the internationalization of the staffing industry", in: Global Networks, 5,1: 3-26.

Phetsiriseng, Inthasone, 2007: Gender Concerns in Migration in Lao PDR. Migration mapping study: A review of trends, policy and programme initiatives (Bangkok: UNIFEM East and Southeast Asia, and Unifem Lao PDR).

Pholsena, Vatthana; Banomyong, Ruth, 2006: Laos: From buffer state to crossroads? (Chiang Mai: Mekong Press).

Pijpers, Roos, 20I0: "International Employment Agencies and Migrant Flexiwork in an Enlarged European Union", in: Journal of Ethnic and Migration Studies, 36,7: 1079I097.

Pongkhao, Somsack, 2007: "Lao Authorities Demand Legalisation of Workers", in: Thailand' Vientiane Times, 3 September 2007 (issue 206), Vientiane.

Prime Minister's Office, Lao PDR, 2002: Decree of the Prime Minister on Sending Lao Workers to Work Abroad [unofficial translation], No. 68/2002 28th May 2002.

Ricklefs, M.C.; Lockhart, Bruce; Lau, Albert; Reyes, Portia; Aung-Thwin, Maitrii, 20I0: A New History of Southeast Asia (Basingstoke: Palgrave MacMillan). 
Rigg, Jonathan, 2005: Living with Transition in Laos: Market integration in Southeast Asia (London: RoutledgeCurzon).

Rudnyckyj, Daromir, 2004: “Technologies of Servitude: Governmentality and Indonesian transnational labor migration”, in: Anthropological Quarterly, 77.3: 407-434.

Sangsomboun, Phonesavanh, 2008: "Traditional Dress Key to Preserving Culture”, in: Vientiane Times, 59,Io (Vientiane: Io March 2008).

Souksavath, Phonesaly; Acharya, Sarthi, 2009: Employment and Livelihoods: The 4 th national human development report (Vientiane: Ministry of Planning and Investment, UNDP).

Tambiah, S.J., 1984: The Buddhist saints of the forest and the cult of amulets (Cambridge: Cambridge University Press).

Thai, Hung Cam, 20I2: "Low-wage Vietnamese Immigrants, Social Class and Masculinity in the Homeland", in: Ford, Michele; Lyons, Lenore (Eds.) Men and Masculinities in Southeast Asia (London, New York: Routledge): 56-67.

Thammavongsa, Panyasith, 2006: "Permit system vital to control migration”, in: Vientiane Times, I6 January 2006 (Vientiane).

Theeravit, Khien; Semyaem, Adisorn, 2002: Thai-Lao Relations in Laotian Perspective (Bangkok: Institute of Asian Studies, Chulalongkorn University).

UN General Assembly, 2000: Protocol to Prevent, Suppress and Punish Trafficking in Persons, Especially Women and Children, Supplementing the United Nations Convention against Transnational Organized Crime, I5 November 2000; at: 〈http://www.unhcr.org/refworld/ docid/4720706co.html> (I7 March 2009).

UN-ESCAP, 2000: Sexually Abused and Sexually Exploited Children and Youth in the Greater Mekong Subregion: A qualitative assessment of their health needs and available services. ST/ESCAP/2045 (New York: United Nations Economic and Social Commission for Asia and the Pacific).

UNIAP, (n.d.): "Initiatives: Support to underserved victims"; at: <http://www.no-trafficking.org/init_underserved. html> (3I August, 20IO).

Vientiane Times, 2005: "Laos to Export Legal Labour to Thailand", in: Vientiane Times, 5 August 2005 (Vientiane).

Vijayan, Prem, 2002: "Nationalism, Masculinity and the Developmental State: Exploring Hindutva masculinities”, in: Cleaver, Frances (Ed.): Masculinities Matter! Men, gender and development (London, New York: Zed Books): 28-56.

World Bank, 2006: Labor Migration in the Greater Mekong Sub-region. Synthesis report: Phase I (Washington, D.C.: The World Bank).

Xiang, Biao, 20I2: "Predatory Princes and Princely Peddlers: The state and international labour migration intermediaries in China", in: Pacific Affairs, 85,I: 47-68.

Open Access. This chapter is distributed under the terms of the Creative Commons Attribution Non-commercial License, which permits any noncommercial use, distribution, and reproduction in any medium, provided the original author(s) and source are credited. 